\title{
Inserting Tropical Dry Forests Into the Discussion on Biome Transitions in the Tropics
}

\author{
Kyle G. Dexter ${ }^{1,2 *}$, R. Toby Pennington ${ }^{2,3}$, Ary T. Oliveira-Filho ${ }^{4}$, Marcelo L. Bueno ${ }^{5}$, \\ Pedro L. Silva de Miranda ${ }^{1}$ and Danilo M. Neves ${ }^{4,6}$ \\ 'School of GeoSciences, University of Edinburgh, Edinburgh, United Kingdom, ${ }^{2}$ Royal Botanic Garden Edinburgh, \\ Edinburgh, United Kingdom, ${ }^{3}$ Geography, University of Exeter, Exeter, United Kingdom, ${ }^{4}$ Departamento de Botânica, \\ Universidade Federal de Minas Gerais, Belo Horizonte, Brazil, ${ }^{5}$ Laboratório de Ecologia e Evolução de Plantas, Universidade \\ Federal de Viçosa, Viçosa, Brazil, ${ }^{6}$ Department of Ecology and Evolutionary Biology, University of Arizona, Tucson, AZ, \\ United States
}

\section{OPEN ACCESS}

Edited by: Colin Osborne,

University of Sheffield,

United Kingdom

Reviewed by:

Imma Oliveras,

University of Oxford, United Kingdom Liam Jude Langan,

Senckenberg Biodiversität und Klima Forschungszentrum (SBiK-F),

Germany

${ }^{*}$ Correspondence:

Kyle G. Dexter

kyle.dexter@ed.ac.uk

Specialty section:

This article was submitted to Biogeography and Macroecology, a section of the journal

Frontiers in Ecology and Evolution

Received: 01 May 2018 Accepted: 29 June 2018 Published: 24 July 2018

Citation

Dexter KG, Pennington RT, Oliveira-Filho AT, Bueno ML, Silva de Miranda PL and Neves DM (2018) Inserting Tropical Dry Forests Into the Discussion on Biome Transitions in the Tropics. Front. Ecol. Evol. 6:104 doi: 10.3389/fevo.2018.00104
Tropical moist forests and savannas are iconic biomes. There is, however, a third principal biome in the lowland tropics that is less well known: tropical dry forest. Discussions on responses of vegetation in the tropics to climate and land-use change often focus on shifts between forests and savannas, but ignore dry forests. Tropical dry forests are distinct from moist forests in their seasonal drought stress and consequent deciduousness and differ from savannas in rarely experiencing fire. These factors lead tropical dry forests to have unique ecosystem function. Here, we discuss the underlying environmental drivers of transitions among tropical dry forests, moist forests and savannas, and demonstrate how incorporating tropical dry forests into our understanding of tropical biome transitions is critical to understanding the future of tropical vegetation under global environmental change.

Keywords: tropical dry forest, tropical moist forest, savanna, biomes, fire, soil fertility, water stress, deciduousness

\section{INTRODUCTION}

Predicting vegetation change in the tropics depends on understanding the drivers of transitions among major vegetation types, or biomes. Climatic factors, such as mean annual precipitation (MAP) and its seasonality are of obvious importance, but edaphic factors, and disturbance via fire, humans and herbivores also play key roles. Recent large-scale studies across the tropics have focused on transitions between forest and savanna (Hirota et al., 2011; Staver et al., 2011; Oliveras and Malhi, 2016; Xu et al., 2016; Langan et al., 2017). While there is value to simplifying vegetation concepts in the tropics, we believe the simplification used by these authors in defining "forest" goes perhaps one step too far. There are two principal kinds of forest in the lowland tropics, moist forests and dry forests. With very few exceptions (e.g., Hirota et al., 2010; Lehmann et al., 2011), studies of biome transitions in the tropics have either failed to distinguish them, or have completely ignored dry forests, focusing solely on moist forests when using the term "forest." The aim of this perspective is to discuss biome transitions in the tropics and their underlying drivers, while including dry forests in the discussion. We focus on transitions among savanna, moist forest and dry forest, the three biomes in the lowland tropics with a substantial tree component.

Tropical moist forest and savanna are relatively well understood at a global scale compared to tropical dry forests (Pennington et al., 2018). Moist forest is tall, multi-stratal, and with a closed canopy. Tropical moist forests include tropical rain forests, as well as forests with lower rainfall where soil moisture is maintained throughout the year, via edaphic factors such as proximity to 
rivers, or water recycling, allowing most trees to be evergreen (Guan et al., 2015). The understory is often dominated by saplings of taller-statured tree species, although small tree and shrub species are present. Terrestrial forbs and grasses are a minor component of diversity and biomass. Savanna is a more open environment, where tree species are present, but individuals do not form a closed canopy. There is a significant understory grass component, which is flammable, and fires are common. Tree species that occur in savannas are adapted to these recurring fires (Simon and Pennington, 2012), and regular fires are necessary for the maintenance of savanna biodiversity (Parr et al., 2014; Durigan and Ratter, 2016; Abreu et al., 2017). Some savannas in the paleotropics (e.g., miombo woodlands in Africa, deciduous dipterocarp forests in southeast Asia) are generally referred to as dry forests, but we consider them as savannas given that they have a grassy understory and experience regular fire (Ratnam et al., 2011; Dexter et al., 2015; Pennington et al., 2018).

Tropical dry forests vary greatly in structure, from tall, closed canopy forest to short scrub vegetation, occasionally not forming a closed canopy, especially in drier areas (Pennington et al., 2000). They are distinct from savanna in not having a significant grass component and not experiencing regular fires (Murphy and Lugo, 1986; Gentry, 1995). In fact, regular fires would be lethal for many of the characteristic life forms and taxa of tropical dry forest (e.g., cacti; Mooney et al., 1995). This is not to say that dry forests never experience fires. Even moist forests can experience fire under extreme drought conditions (Aragão et al., 2016). Rather, damaging fire is sufficiently rare in dry forests such that fire-intolerant species can persist in the landscape as metapopulations (Hanski, 1998). The exact threshold of fire return interval or intensity involved in the tropical dry forest savanna transition is poorly understood and likely to vary with the broader environmental context (e.g., soil fertility and annual precipitation; Hoffmann et al., 2012; Murphy and Bowman, 2012), and we suggest that this should be a priority for further study. Tropical dry forest is distinct from moist forest in its seasonal drought stress, which leads many tree species to lose their leaves in the dry season (Reich and Borchert, 1984; Murphy and Lugo, 1986). The combination of seasonal drought stress and lack of fire leads to ecosystem function in dry forests that is markedly different from savannas or moist forests, which justifies their distinction as a unique biome.

\section{BIOMES IN LOWLAND TROPICAL SOUTH AMERICA}

We focus this review on continental lowland tropical South America (LTSA), where we have conducted most of our research. In a recent study (Silva de Miranda et al., in press), we used an unsupervised classification, or hierarchical clustering, of sites based on their tree species composition (see inset in Figure 1), followed by interpretation of the resulting cluster using site information on vegetation physiognomy (savanna vs. forest) and leaf flush regime (evergreen vs. semideciduous vs. deciduous) to delimit and map biomes across LTSA east of the Andes (Figure 1). Moist forests fell in two major groups in the cluster and occurred in two large geographic blocks, one in the Amazon basin and another along the Atlantic coast of Brazil. Semideciduous forests did not form a distinct group in the cluster and were instead mixed with evergreen, moist forest sites. Semideciduous forests are often found in drier regions, where they occur along rivers, lake margins and submontane areas with orographic precipitation. Savanna formed a single group in the cluster and was most prevalent in central Brazil, in an area commonly termed the Cerrado.

Tropical dry forest also formed a single group in the cluster, which was comprised almost entirely of forest sites with deciduous phenology. In LTSA, the largest block of dry forest occurs in the Caatinga region of northeast Brazil. The Caatinga has been referred to as a biome (Hirota et al., 2010; Instituto Brasileiro de Geografia e Estatística, 2012), although as a region it contains non-dry forest habitat (e.g., patches of savanna). Further, tropical dry forest is found outside of the Caatinga, in patches throughout the Cerrado, in an area spanning the Pantanal and Chiquitania in Bolivia (Figure 1), and scattered more widely across the Neotropics (DRYFLOR, 2016). While Silva de Miranda et al. (in press) broadly assessed climatic overlaps amongst biomes, they did not focus on the environmental drivers of transitions between individual biomes. That is the goal of the present manuscript.

\section{TRANSITIONS BETWEEN TROPICAL SAVANNA AND DRY FORESTS}

A common view of dry forests in the tropics is that they are transitional between savannas and moist forests along precipitation gradients (e.g., Whittaker, 1970; Malhi et al., 2009). If, however, we examine how the sites featured in Figure $\mathbf{1}$ are distributed over variation in MAP (Figure 2), a more complex picture emerges. Moist forests do occur under wetter conditions than savanna, but dry forests are largely found under drier conditions. Below 1,000 mm MAP, savanna quickly disappears and dry forest becomes the only tree-dominated vegetation type. The largest area of these arid dry forests is found in the Caatinga region of northeast Brazil. As discussed above, a key distinction between savanna and dry forest is the regularity of fire, and in these dry conditions, there is not sufficient biomass build-up to sustain regular fires (Van Der Werf et al., 2008). In particular, this reflects the relative lack of grasses. The tree species that are present are able to tolerate severe drought, but they do not invest in adaptations for fire, such as thick bark or underground stems, characteristic of savanna species (Simon and Pennington, 2012).

There is also extensive occurrence of the dry forest biome under the same precipitation conditions as savanna. These are dry forests found in the Cerrado region and around the Pantanal and Chiquitania regions of Brazil and Bolivia. Within the Cerrado, dry forests are known to occur on and around calcareous outcrops, where soils have higher phosphorus and base cation concentrations (Ratter et al., 1978; Furley and Ratter, 1988; Oliveira-Filho and Ratter, 2002; Neves et al., 2015). On these soils, trees can grow more quickly, have better chances of escaping the "fire trap" and are more likely to 


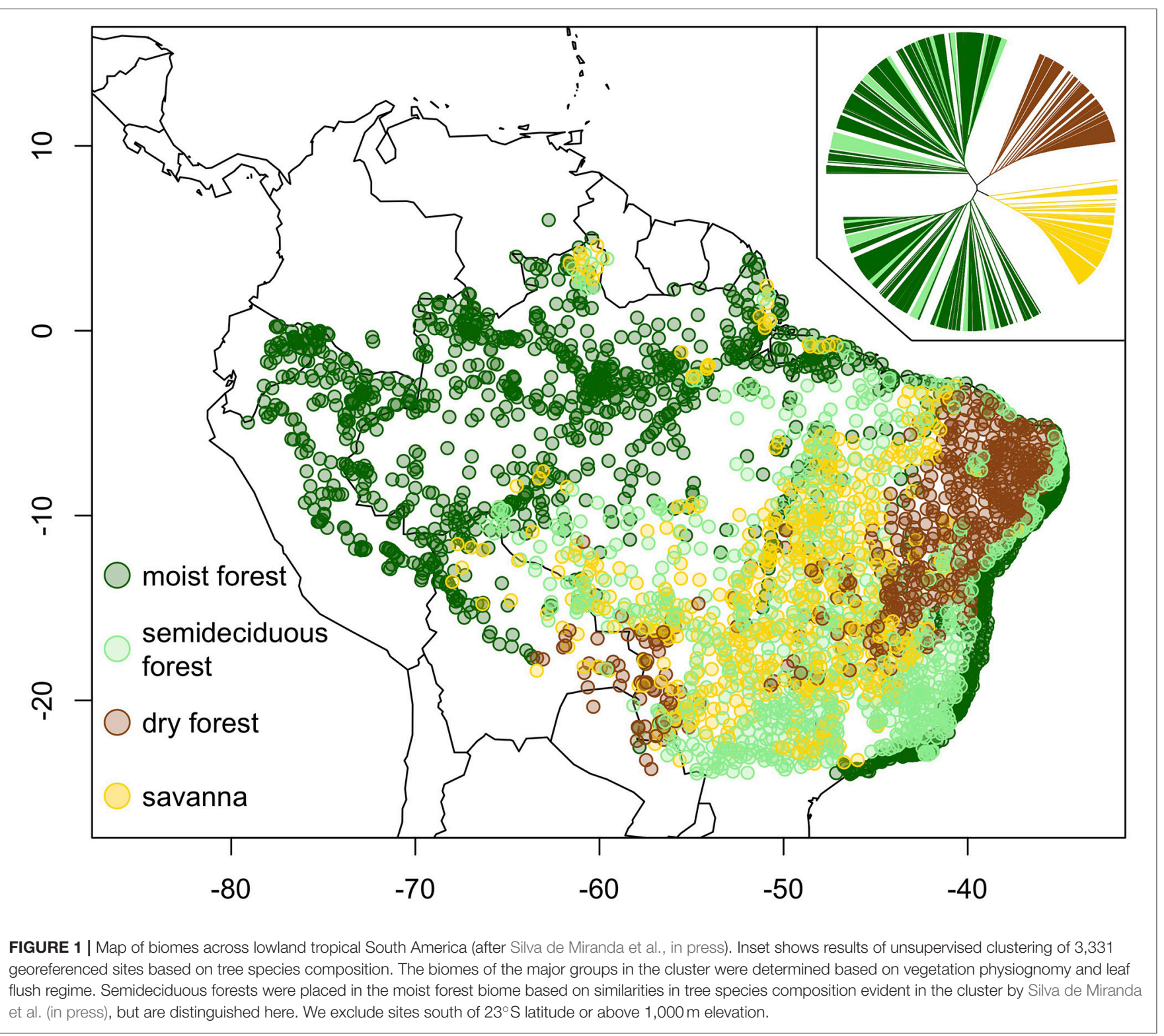

form a closed canopy (Hoffmann et al., 2009). There can be positive feedbacks between tree growth, grass exclusion and fire mitigation that leads to a forested vegetation (Hoffmann et al., 2012; Silva et al., 2013; Pausas and Dantas, 2017). Calcareous outcrops in the Cerrado also have poorly developed, shallow soils, and vegetation occurring on them may experience greater drought stress than surrounding vegetation, thus making them similar to the arid dry forests, which lack fire because of insufficient fuel build-up. However, it is likely that soil fertility is relevant for the presence of dry forests around calcareous outcrops as a different vegetation, cerrado rupestre, which is floristically related to savanna vegetation, is found on noncalcareous outcrops in the Cerrado (Ribeiro and Walter, 1998). Whichever factor is more important (soils with high fertility or low water-holding capacity), it is evident that the same drought-tolerant, fire-intolerant tree species and lineages that dominate vegetation in the arid Caatinga are also found in dry forest patches in the moister Cerrado (Prado and Gibbs, 1993; Neves et al., 2015; DRYFLOR, 2016; Silva de Miranda et al., in press).

Dry forest and savanna vegetation also intermingle in the Chiquitania region of Bolivia, but here dry forest predominates and savanna occurs in patches, which may be because soils in the Chiquitania are more fertile on average than in the Cerrado (Silva de Miranda et al., in press). Some of the savannas that are present in the Chiquitania region may represent dry forest that has been degraded by logging or anthropogenic fire (Devisscher et al., 2016), highlighting that human land-use patterns can readily drive transitions between dry forest and savanna. However, "oldgrowth savannas" that would exist independent of anthropogenic 


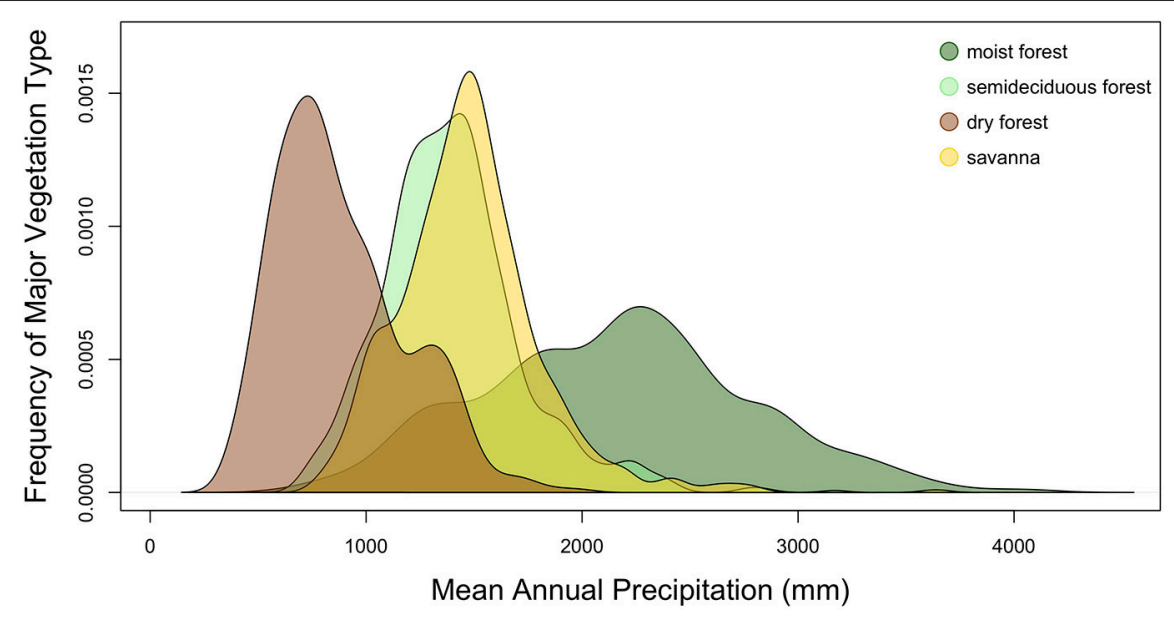

FIGURE 2 | Frequency distribution of sites in Figure 1 over a gradient in mean annual precipitation. For heuristic purposes, semideciduous and moist forests are distinguished although they may represent the same biome.

influence are also clearly present in Bolivia (Power et al., 2016; Veldman, 2016).

If fire is excluded from savanna vegetation, it first converts to a formation with a higher percentage of tree canopy cover termed "cerradão" (Durigan and Ratter, 2006, 2016), which translates from the Portuguese as "big cerrado" and is generally considered as a forest. Cerradão shares some tree species with tropical dry forest and comparatively few with semideciduous and evergreen moist forests (Bueno et al., 2018), even though the latter are present near savanna vegetation along river courses and lake margins that have year-round water availability (Ribeiro and Walter, 1998). Tree species from semideciduous and evergreen forests may be less likely to immigrate into cerradão than typical dry forest tree species because they are not adapted to seasonal drought. While cerradão is initially comprised of fire-adapted tree species from the cerrado, dry forest tree species colonize this environment if propagules are available, fire remains absent and soils are sufficiently fertile. These dry forest tree species may eventually outcompete cerrado tree species, since they do not invest in fire defense (Ratajczak et al., 2017), and in the prolonged absence of fire, cerradão may transition to a dry forest if there are positive feedback cycles between forest vegetation, lack of fire and soil fertility (Silva et al., 2013; Pellegrini et al., 2014, 2018). However, if the underlying soils remain poor and/or if there are high aluminum concentrations in the soil that do not attenuate over time, then cerrado tree species, which are adapted to infertile, aluminum-rich soils may continue to dominate the vegetation.

Overall, the savanna-dry forest transition is distinct from the savanna-moist forest transition in two key ways: (1) the contrasting role of water availability (lowest in dry forest, intermediate in savanna and highest in moist forest) and (2) the potentially critical importance of soil fertility for the savannadry forest transition (savanna and moist forests are similar in generally having infertile, acidic soils).

\section{TRANSITIONS BETWEEN MOIST FOREST AND DRY FOREST}

Both of these biomes are forest, but they function in distinct ways. Dry forests are found in areas with marked precipitation seasonality, which leads most species to lose their leaves during the dry season and has significant implications for nutrient cycling (Reich and Borchert, 1984; Murphy and Lugo, 1986). Many moist forests also experience seasonality in water availability (e.g., in the southern and eastern Amazon), but the dry season is three months or less and subsurface water remains available to trees (Guan et al., 2015). The systems also differ in the rate at which they accrue and cycle carbon, with trees in moist forests growing more quickly and storing more total carbon (Murphy and Lugo, 1986; Poorter et al., 2017). There are often differences in soil fertility, with dry forests occurring on more fertile soils, which facilitates their ability to shed their leaves as they can readily afford to grow new ones. However, high rainfall in moist forests results in nutrient leaching, and this correlation between soil fertility and biome identity may be due to overriding climatic factors (Webb, 1968; Hall and Swaine, 1976).

In LTSA, there are multiple areas of contact between the moist and dry forest biomes (Figure 1). One transition zone is in northeastern Brazil, where evergreen Atlantic forest on the coast transitions to dry forest in the arid Caatinga. In between the two lies a band of semideciduous forests. Another transition zone is found in the Chiquitania region of eastern Bolivia and adjacent areas of Brazil, where there is a gradual transition over $200+\mathrm{km}$ of geographic distance, largely covered by semideciduous forest. We suggest that transitions between dry forest and moist forest are primarily mediated by water availability and that intermediate states are possible in zones of intermediate water availability (Oliveira-Filho and Fontes, 2000; Oliveira-Filho et al., 2006). This contrasts with transitions between savanna and moist forest that can be more abrupt and may represent alternative stable states (although see Lloyd and Veenendaal, 2016). 


\section{SEMIDECIDUOUS FORESTS}

Previous studies have variously grouped semideciduous forests with the dry forest biome (Murphy and Lugo, 1986; Pennington et al., 2000) or the moist forest biome (DRYFLOR, 2016; Silva de Miranda et al., in press). In fact, as discussed above, these forests may be transitional between the two. Semideciduous forests in LTSA have few endemic tree species and instead contain tree species associated with the dry or moist forest biomes (OliveiraFilho and Fontes, 2000). As moist forests contain many more tree species than dry forests (Esquivel-Muelbert et al., 2017), we suggest that they may contribute more species to semideciduous forests simply via mass effects (Shmida and Wilson, 1985), and this may be why they group with moist forests in clustering analyses based on presence versus absence of tree species (as in Silva de Miranda et al., in press). If abundance information were to be taken into account (e.g., via inventory plot data), we hypothesize that semideciduous forests may cluster with moist or dry forest based on the proportion of individuals belonging to moist versus dry forest tree species. It is clear that future comparative studies across dry, moist and semideciduous forests are needed to understand their origins and how they compare in terms of ecosystem function. Their geographically variable species composition and lack of endemic species suggests that semideciduous forests may have been independently and recently assembled in different ecotonal areas.

\section{BIOME TRANSITIONS TO DRY FOREST OUTSIDE THE NEOTROPICS}

As in South America, moist forest-savanna transitions have been studied extensively on other continents, but transitions to dry forest have received less attention. This is partly because it is unclear where dry forest exists outside of the Neotropics (Lock, 2006; Dexter et al., 2015; Pennington et al., 2018). In a recent study, Linder (2014) delimited and described the main "floras" of Africa, which are large-scale units of vegetation that have a distinct evolutionary and biogeographic history and differ in their present-day plant taxonomic composition. Linder did not assign the term "biome" to these vegetation units, although his "floras" correspond to several previously defined biomes. There is a "savanna flora," which readily corresponds to the savanna biome, and a "lowland forest flora" that largely corresponds to the moist forest biome. Linder postulated an "arid flora" that is most evident in the Horn of Africa (Somalia, Ethiopia and northern Kenya), but is also present in arid regions of Angola and Namibia. The distribution of this "arid flora" largely overlaps the distribution of the "succulent biome" in Africa, as proposed by Schrire et al. (2005). The "arid flora" or "succulent biome" is similar to dry forest in arid regions of the Neotropics in that there is not adequate water availability to allow for sufficient biomass build-up to sustain regular fires. Thus, as in the Neotropics, water availability may be one environmental factor that underlies transitions between savanna and dry forest in Africa.

Soil fertility is another significant factor that has been shown to underlie savanna-dry forest transitions in the Neotropics.
An important question for future research in Africa is whether, amongst its great expanses of savanna, there is distinct vegetation that does not regularly burn, is found on more fertile soils and shows greater floristic similarity with the "arid flora" of Linder (2014) than it does with surrounding savanna vegetation. It may be that in Africa, a higher abundance of large herbivores, including elephants, favors grasses over trees, leading to a more open savanna vegetation with more frequent fires, even in areas of higher soil fertility (Charles-Dominique et al., 2016; Pellegrini et al., 2017). If dry forests are not found on fertile soils in more mesic areas of Africa, there may not be moist forest-dry forest transitions on this continent, because the areas mapped as belonging to the "arid flora" or "succulent biome" are completely separated from moist forest regions by large areas of savanna (Schrire et al., 2005; Linder, 2014).

In the tropical regions of continental Asia and in Malesia, moist forest is the predominant vegetation type, although drier forest formations are present (e.g., deciduous forests in the Western Ghats and dry dipterocarp forests in Indochina). As we have discussed elsewhere (Dexter et al., 2015; Pennington et al., 2018), the majority of these drier forest formations have a significant grassy component in the understory, burn regularly and may be better considered as savannas (Ratnam et al., 2011). The succulent biome of Schrire et al. (2005) is mapped as present in arid regions of northwest India and extending across the coast of Pakistan and Iran to the Arabian Peninsula. Thus, an arid form of the dry forest biome may occur in Asia, as in Africa, and water availability may underlie transitions between vegetation in seasonally dry areas that regularly burns (what we term savanna) and that does not regularly burn (what we term dry forest). As with Africa, future research in Asia should assess if there are vegetation formations in seasonally dry, yet not arid, areas that: (1) are found on fertile soils, (2) do not regularly burn and (3) show greater floristic similarity with arid areas than with surrounding vegetation that does regularly burn. This will help determine if soil fertility is also important in understanding savanna-dry forest transitions in Asia, as it is in the Neotropics.

\section{CONCLUSIONS}

The aim of this perspective has been to bring the tropical dry forest biome into discussions of biome transitions in the tropics. Previous studies of tropical biome transitions have largely focused on forest-savanna transitions, with all forests being considered as a single biome. In fact, there are many kinds of forests in the tropics, some of which are distinct from each other in species composition and ecosystem function and represent different biomes (i.e., dry vs. moist forest) and others which are more difficult to classify (e.g., semideciduous forests, cerradão). Water availability is a key factor underlying tropical biome transitions. While forests are often thought to occur under wetter conditions than savannas, tropical dry forest is actually more prevalent in areas of lower water availability $(<1,000 \mathrm{~mm}$ MAP). Meanwhile, soil fertility, which has received limited attention in studies of biome transitions, is also critical in the Neotropics, and merits future research on other continents. More generally, 
recognizing tropical dry forest as a distinct biome within the tropics should improve the accuracy of modeling studies that aim to predict the future of tropical vegetation and ecosystem function under global environmental change.

\section{AUTHOR CONTRIBUTIONS}

KD and RP wrote the first draft of the manuscript and contributed to revising the manuscript. AO-F, MB, PS and DN contributed to revising and improving the manuscript.

\section{REFERENCES}

Abreu, R. C. R., Hoffmann, W. A., Vasconcelos, H. L., Pilon, N. A., Rossatto, D. R., and Durigan, G. (2017). The biodiversity cost of carbon sequestration in tropical savanna. Sci. Adv. 3:e1701284. doi: 10.1126/sciadv.1701284

Aragão, L. E., Anderson, L. O., Lima, A., and Arai, E. (2016). "Fires in Amazonia," in Interactions Between Biosphere, Atmosphere and Human Land Use in the Amazon Basin, eds L. Nagy, B. R. Forsberg, and P. Artaxo (Heidelberg: Springer), 301-329.

Bueno, M. L., Dexter, K. G., Pennington, R. T., Pontara, V., Neves, D. M., Ratter, J. A., et al. (2018). The environmental triangle of the Cerrado domain: ecological factors driving shifts in tree species composition between forests and savannas. J. Ecol. doi: 10.1111/1365-2745.12969

Charles-Dominique, T., Davies, T. J., Hempson, G. P., Bezeng, B. S., Daru, B. H., Kabongo, R. M., et al. (2016). Spiny plants, mammal browsers, and the origin of African savannas. Proc. Natl. Acad. Sci. U.S.A. 113, E5572-E5579. doi: $10.1073 /$ pnas. 1607493113

Devisscher, T., Anderson, L. O., Aragão, L. E., Galván, L., and Malhi, Y. (2016). Increased Wildfire Risk Driven by Climate and Development Interactions in the Bolivian Chiquitania, Southern Amazonia. PLoS ONE 11:e0161323. doi: 10.1371/journal.pone.0161323

Dexter, K. G., Smart, B., Baldauf, C., Baker, T. R., Balinga, M. B., Brienen, R. J. W., et al. (2015). Floristics and biogeography of vegetation in seasonally dry tropical regions. Int. For. Rev. 17, 10-32. doi: 10.1505/146554815815834859

DRYFLOR, Banda, R. K., Delgado-Salinas, A., Dexter, K. G., Linares-Palomino, R., Oliveira-Filho, A., et al. (2016). Plant diversity patterns in neotropical dry forests and their conservation implications. Science 353, 1383-1387. doi: $10.1126 /$ science.aaf5080

Durigan, G., and Ratter, J. A. (2006). Successional changes in cerrado and cerrado/forest ecotonal vegetation in western São Paulo State, Brazil, 1962-2000. Edinburgh J. Bot. 63, 119-130. doi: 10.1017/S0960428606 000357

Durigan, G., and Ratter, J. A. (2016). The need for a consistent fire policy for Cerrado conservation. J. Appl. Ecol. 53, 11-15. doi: 10.1111/1365-2664.12559

Esquivel-Muelbert, A., Baker, T. R., Dexter, K. G., Lewis, S. L., Steege, H., LopezGonzalez, G., et al. (2017). Seasonal drought limits tree species across the Neotropics. Ecography 40, 618-629. doi: 10.1111/ecog.01904

Furley, P. A., and Ratter, J. A. (1988). Soil resources and plant communities of the central Brazilian cerrado and their development. J. Biogeogr. 97-108. doi: $10.2307 / 2845050$

Gentry, A. H. (1995). "Diversity and floristic composition of neotropical dry forests,"in Seasonally dry tropical forests, eds S.H. Bullock, H.A. Mooney, and E. Medina (Cambridge: Cambridge University Press), 146-194.

Guan, K., Pan, M., Li, H., Wolf, A., Wu, J., Medvigy, D., et al. (2015). Photosynthetic seasonality of global tropical forests constrained by hydroclimate. Nat. Geosci. 8, 284-289. doi: 10.1038/ngeo2382

Hall, J. B., and Swaine, M. (1976). Classification and ecology of closed-canopy forest in Ghana. J. Ecol. 64, 913-951. doi: 10.2307/2258816

Hanski, I. (1998). Metapopulation dynamics. Nature 396, 41-49. doi: $10.1038 / 23876$

Hirota, M., Holmgren, M., Van Nes, E. H., and Scheffer, M. (2011). Global resilience of tropical forest and savanna to critical transitions. Science 334, 232-235. doi: 10.1126/science.1210657

\section{FUNDING}

KD, RP, and DN thank the Natural Environment Research Council (UK) for funding via NE/I028122/1. KD thanks the Leverhulme Trust for supporting him during the time this study was completed via an International Academic Fellowship. PS thanks the Coordenação de Aperfeiçoamento de Pessoal de Nível Superior-Brazil (CAPES) for support via the Science without Borders Programme (grant 99999.013197/ 2013-04).

Hirota, M., Nobre, C., Oyama, M. D., and Bustamante, M. (2010). The climatic sensitivity of the forest, savanna and forest-savanna transition in tropical South America. New Phytol. 187, 707-719. doi: 10.1111/j.1469-8137.2010.03352.x

Hoffmann, W. A., Adasme, R., Haridasan, M. T., de Carvalho, M., Geiger, E. L., Pereira, M. A., et al. (2009). Tree topkill, not mortality, governs the dynamics of savanna-forest boundaries under frequent fire in central Brazil. Ecology 90, 1326-1337. doi: 10.1890/08-0741.1

Hoffmann, W. A., Geiger, E. L., Gotsch, S. G., Rossatto, D. R., Silva, L. C., Lau, O. L., et al. (2012). Ecological thresholds at the savanna-forest boundary: how plant traits, resources and fire govern the distribution of tropical biomes. Ecol. Lett. 15, 759-768. doi: 10.1111/j.1461-0248.2012.01789.x

Instituto Brasileiro de Geografia e Estatística (ed.). (2012). Manual Técnico da Getveação Brasileira (2a Edição Revista e Ampliada). Rio de Janeiro: Instituto Brasileiro de Geografia e Estatística-IBGE.

Langan, L., Higgins, S. I., and Scheiter, S. (2017). Climate-biomes, pedo-biomes or pyro-biomes: which world view explains the tropical forest-savanna boundary in South America? J. Biogeogr. 44, 2319-2330. doi: 10.1111/jbi.13018

Lehmann, C. E., Archibald, S. A., Hoffmann, W. A., and Bond, W. J. (2011). Deciphering the distribution of the savanna biome. New Phytol. 191, 197-209. doi: 10.1111/j.1469-8137.2011.03689.x

Linder, H. P. (2014). The evolution of African plant diversity. Front. Ecol. Evol. 2:38. doi: $10.3389 /$ fevo.2014.00038

Lloyd, J., and Veenendaal, E. M. (2016). Are fire mediated feedbacks burning out of control. Biogeosci. Discuss. 2016, 1-20. doi: 10.5194/bg-2015-660

Lock, J. M. (2006). “The seasonally dry vegetation," in Neotropical Savannas and Seasonally Dry Forests: Plant Diversity, Biogeography, and Conservation (Boca Raton, FL: Taylor and Francis), 449.

Malhi, Y., Aragão, L. E., Galbraith, D., Huntingford, C., Fisher, R., Zelazowski, P., et al. (2009). Exploring the likelihood and mechanism of a climate-changeinduced dieback of the Amazon rainforest. Proc. Nat. Acad. Sci. U.S.A. 106, 20610-20615. doi: 10.1073/pnas.0804619106

Mooney, H. A., Bullock, S. H., and Medina, E. (1995). “Introduction," in Seasonally Dry Tropical Forests, eds S. H. Bullock, H. A. Mooney, and E. Medina (Cambridge: Cambridge University Press), 1-8.

Murphy, B. T., and Bowman, D. M. (2012). What controls the distribution of tropical forest and savanna? Ecol. Lett. 15, 748-758. doi: 10.1111/j.1461-0248.2012.01771.x

Murphy, P. G., and Lugo, A. E. (1986). Ecology of tropical dry forest. Annu. Rev. Ecol. Syst. 17, 67-88. doi: 10.1146/annurev.es.17.110186.000435

Neves, D. M., Dexter, K. G., Pennington, R. T., Bueno, M. L., and Oliveira Filho, A. T. (2015). Environmental and historical controls of floristic composition across the South American Dry Diagonal. J. Biogeogr. 42, 1566-1576. doi: $10.1111 /$ jbi.12529

Oliveira-Filho, A. T., and Fontes, M. A. L. (2000). Patterns of floristic differentiation among Atlantic forests in southeastern Brazil and the influence of climate. Biotropica 32, 793-810. doi: 10.1111/j.1744-7429.2000.tb00619.x

Oliveira-Filho, A. T., Jarenkow, J. A., and Rodal, M. J. N. (2006). "Floristic relationships of Seasonally Dry Forest of eastern South American based on tree species distribution patterns," in Neotropical Savannas and Dry Forests: Plant Diversity, Biogeography and Conservation, eds R. T. Lewis, G. P. Ratter, and J. A. (Orgs.) (Pennington, NJ: Boca Raton: CRC Press), 159-192.

Oliveira-Filho, A. T., and Ratter, J. A. (2002). "Vegetation physiognomies and woody flora of the cerrado biome: ecology and natural history of a neotropical 
Savanna," in The Cerrados of Brazil, eds P. S. Oliveira and R. J. Marquis (New York, NY: Columbia University Press), 91-120.

Oliveras, I., and Malhi, Y. (2016). Many shades of green: the dynamic tropical forest-savannah transition zones. Phil. Trans. R. Soc. B. Biol. Sci. 371:20150308. doi: $10.1098 /$ rstb.2015.0308

Parr, C. L., Lehmann, C. E., Bond, W. J., Hoffmann, W. A., and Andersen, A. N. (2014). Tropical grassy biomes: misunderstood, neglected, and under threat. Trends Ecol. Evol. 29, 205-213. doi: 10.1016/j.tree.2014.02.004

Pausas, J. G., and Dantas, V. D. L. (2017). Scale matters: fire-vegetation feedbacks are needed to explain tropical tree cover at the local scale. Glob. Ecol. Biogeogr. 26, 395-399. doi: 10.1111/geb.12562

Pellegrini, A. F., Ahlström, A., Hobbie, S. E., Reich, P. B., Nieradzik, L. P., Staver, A. C., et al. (2018). Fire frequency drives decadal changes in soil carbon and nitrogen and ecosystem productivity. Nature 553, 194-198. doi: 10.1038 /nature 24668

Pellegrini, A. F., Hoffmann, W. A., and Franco, A. C. (2014). Carbon accumulation and nitrogen pool recovery during transitions from savanna to forest in central Brazil. Ecology 95, 342-352. doi: 10.1890/13-0290.1

Pellegrini, A. F., Pringle, R. M., Govender, N., and Hedin, L. (2017). Woody plant biomass and carbon exchange depend on elephant-fire interactions across a productivity gradient in African savanna. J. Ecol. 105, 111-121. doi: $10.1111 / 1365-2745.12668$

Pennington, R. T., Lehmann, C. E. R., and Rowland, L. M. (2018). Tropical savannas and dry forests. Curr. Biol. 28, R541-R545. doi: 10.1016/j.cub.2018.03.014

Pennington, R. T., Prado, D. E., and Pendry, C. A. (2000). Neotropical seasonally dry forests and Quaternary vegetation changes. J. Biogeogr. 27, 261-273. doi: 10.1046/j.1365-2699.2000.00397.x

Poorter, L., van der Sande, M. T., Arets, E. J., Ascarrunz, N., Enquist, B., Finegan, B., et al. (2017). Biodiversity and climate determine the functioning of Neotropical forests. Glob. Ecol. Biogeogr. 26, 1423-1434. doi: 10.1111/geb.12668

Power, M. J., Whitney, B. S., Mayle, F. E., Neves, D. M., de Boer, E., and MacLean, K. S. (2016). Fire, climate and vegetation linkages in the Bolivian Chiquitano Seasonally Dry Tropical Forest. Philos. Trans. R. Soc. B. Biol. Sci. 371:20150165. doi: 10.1098/rstb.2015.0165

Prado, D. E., and Gibbs, P. E. (1993). Patterns of species distributions in the dry seasonal forests of South America. Annu. Mol. Bot. Gard. 80, 902-927. doi: $10.2307 / 2399937$

Ratajczak, Z., D'Odorico, P., and Yu, K. (2017). The Enemy of My Enemy Hypothesis: Why Coexisting with Grasses May Be an Adaptive Strategy for Savanna Trees. Ecosystems 20, 1278-1295. doi: 10.1007/s10021-0170110-7

Ratnam, J., Bond, W. J., Fensham, R. J., Hoffmann, W. A., Archibald, S., Lehmann, C. E., et al. (2011). When is a 'forest' a savanna, and why does it matter? Glob. Ecol. Biogeogr. 20, 653-660. doi: 10.1111/j.1466-8238.2010.00634.x

Ratter, J. A., Askew, G. P., Montgomery, R. F., and Gifford, D. R. (1978). Observations on forests of some mesotrophic soils in Cental Brazil.(Observacoes sobre florestas de alguns solos mesotroficos no Brasil Central.). Rev. Brasil. Bot. 1, 47-58.
Reich, P. B., and Borchert, R. (1984). Water stress and tree phenology in a tropical dry forest in the lowlands of Costa Rica. J. Ecol. 61-74. doi: 10.2307/2260006

Ribeiro, J. F., and Walter, B. M. T. (1998). "Fitofisionomias do bioma cerrado," in Cerrado: Ambiente e Flora, eds S. M. Sano and S. P. Almeida (Planaltina: Embrapa-CPAC), 89-166.

Schrire, B. D., Lavin, M., and Lewis, G. P. (2005). Global distribution patterns of the Leguminosae: insights from recent phylogenies. Biologiske Skrifter - Det Kongelige Danske Videnskabernes Selskab, 375-422.

Shmida, A. V. I., and Wilson, M. V. (1985). Biological determinants of species diversity. J. Biogeogr. 20, 1-20. doi: 10.2307/2845026

Silva, L. C., Hoffmann, W. A., Rossatto, D. R., Haridasan, M., Franco, A. C., and Horwath, W. R. (2013). Can savannas become forests? A coupled analysis of nutrient stocks and fire thresholds in central Brazil. Plant Soil 373, 829-842. doi: $10.1007 /$ s11104-013-1822-x

Silva de Miranda, P. L., Oliveira-Filho, A., Pennington, R. T., Neves, D. M., Baker, T. R., and Dexter, K. G. (in press). Using tree species inventories to map biomes and assess their climatic overlaps in lowland tropical South America. Global Ecology and Biogeography.

Simon, M. F., and Pennington, T. (2012). Evidence for adaptation to fire regimes in the tropical savannas of the Brazilian Cerrado. Int. J. Plant Sci. 173, 711-723. doi: $10.1086 / 665973$

Staver, A. C., Archibald, S., and Levin, S. A. (2011). The global extent and determinants of savanna and forest as alternative biome states. Science 334, 230-232. doi: 10.1126/science. 1210465

Van Der Werf, G. R., Randerson, J. T., Giglio, L., Gobron, N., and Dolman, A. J. (2008). Climate controls on the variability of fires in the tropics and subtropics. Glob. Biogeochem. Cycles 22:GB3028. doi: 10.1029/2007GB003122

Veldman, J. W. (2016). Clarifying the confusion: old-growth savannahs and tropical ecosystem degradation. Phil. Trans. R. Soc. B.Biol. Sci. 371:20150306. doi: $10.1098 /$ rstb.2015.0306

Webb, L. J. (1968). Environmental relationships of the structural types of Australian rain forest vegetation. Ecology 49, 296-311. doi: 10.2307/1934459

Whittaker, R. H. (1970). Communities and Ecosystems. New York, NY: Macmillan, 162.

Xu, C., Hantson, S., Holmgren, M., van Nes, E. H., Staal, A., and Scheffer, M. (2016). Remotely sensed canopy height reveals three pantropical ecosystem states. Ecology 97, 2518-2521. doi: 10.1002/ecy.1470

Conflict of Interest Statement: The authors declare that the research was conducted in the absence of any commercial or financial relationships that could be construed as a potential conflict of interest.

Copyright (c) 2018 Dexter, Pennington, Oliveira-Filho, Bueno, Silva de Miranda and Neves. This is an open-access article distributed under the terms of the Creative Commons Attribution License (CC BY). The use, distribution or reproduction in other forums is permitted, provided the original author(s) and the copyright owner(s) are credited and that the original publication in this journal is cited, in accordance with accepted academic practice. No use, distribution or reproduction is permitted which does not comply with these terms. 